\title{
Article
}

\section{The Enhanced Hydrogen Storage Capacity of Carbon Fibers: The Effect of Hollow Porous Structure and Surface Modification}

\author{
Sung-Ho Hwang ${ }^{1}$, Young Kwang Kim ${ }^{1}{ }^{\mathbb{D}}$, Hye-Jin Seo ${ }^{1}$, Soon Moon Jeong ${ }^{1}$, Jongwon Kim ${ }^{2, *(\mathbb{D})}$ \\ and Sang Kyoo Lim 1,3,*(D) \\ 1 Division of Energy Technology, DGIST, Daegu 42988, Korea; hsungho@dgist.ac.kr (S.-H.H.); \\ kimyk1211@dgist.ac.kr (Y.K.K.); seohaejin511@dgist.ac.kr (H.-J.S.); smjeong@dgist.ac.kr (S.M.J.) \\ 2 Department of Fiber System Engineering, Yeungnam University, Gyeongsan 38541, Korea \\ 3 Department of Interdisciplinary Engineering, DGIST, Daegu 42988, Korea \\ * Correspondence: kjwfiber@ynu.ac.kr (J.K.); limsk@dgist.ac.kr (S.K.L.)
}

Citation: Hwang, S.-H.; Kim, Y.K.; Seo, H.-J.; Jeong, S.M.; Kim, J.; Lim, S.K. The Enhanced Hydrogen Storage Capacity of Carbon Fibers: The Effect of Hollow Porous Structure and Surface Modification. Nanomaterials 2021, 11, 1830. https://doi.org/ 10.3390/nano11071830

Academic Editor: Christian M. Julien

Received: 1 June 2021

Accepted: 12 July 2021

Published: 14 July 2021

Publisher's Note: MDPI stays neutral with regard to jurisdictional claims in published maps and institutional affiliations.

Copyright: (c) 2021 by the authors. Licensee MDPI, Basel, Switzerland. This article is an open access article distributed under the terms and conditions of the Creative Commons Attribution (CC BY) license (https:/ / creativecommons.org/licenses/by/ $4.0 /)$.

\begin{abstract}
In this study, highly porous carbon fiber was prepared for hydrogen storage. Porous carbon fiber (PCF) and activated porous carbon fiber (APCF) were derived by carbonization and chemical activation after selectively removing polyvinyl alcohol from a bi-component fiber composed of polyvinyl alcohol and polyacrylonitrile (PAN). The chemical activation created more pores on the surface of the PCF, and consequently, highly porous APCF was obtained with an improved BET surface area $\left(3058 \mathrm{~m}^{2} \mathrm{~g}^{-1}\right)$ and micropore volume $\left(1.18 \mathrm{~cm}^{3} \mathrm{~g}^{-1}\right)$ compare to those of the carbon fiber, which was prepared by calcination of monocomponent PAN. APCF was revealed to be very efficient for hydrogen storage, its hydrogen capacity of $5.14 \mathrm{wt} \%$ at $77 \mathrm{~K}$ and $10 \mathrm{MPa}$. Such hydrogen storage capacity is much higher than that of activated carbon fibers reported previously. To further enhance hydrogen storage capacity, catalytic Pd nanoparticles were deposited on the surface of the APCF. The Pd-deposited APCF exhibits a high hydrogen storage capacity of $5.45 \mathrm{wt} \%$ at $77 \mathrm{~K}$ and $10 \mathrm{MPa}$. The results demonstrate the potential of Pd-deposited APCF for efficient hydrogen storage.
\end{abstract}

Keywords: hydrogen storage; microporosity; surface modification; carbon fiber

\section{Introduction}

Future energy security has been threatened by the decrease of fossil fuel resources and the polluting effects of their use. To resolve these issues, there have been tremendous efforts to invent effective renewable energy systems such as geothermal, wind, solar, biomass, and hydrogen energy. Among those candidates, hydrogen has attracted attention as it can replace fossil fuels by achieving both high energy effectiveness and eco-friendliness because of its high gravimetric energy density, and pure byproducts [1-3]. Despite these advantages, the application of hydrogen energy systems for practical use has key technical barriers to be overcome in storage efficiency, low volumetric storage density, durability [4-7], refueling time, cost, and safety issues [8-11]. To solve these problems, both selecting appropriate material and designing their structures, which are able to achieve high performance for hydrogen storage, are required.

In general, hydrogen is stored in one of four different ways: high-pressure compression method, liquefaction within a high-pressure tank, storage in a solid-state hydride, and storage in a porous material [12]. Although the compression and liquefaction were commonly used, the storage of hydrogen molecules via porous materials has been considered as an attractive technique due to the fast reaction kinetics, high adsorption capacity, and improved level of safety compared with that of the compressed-gas storage process. Moreover, liquefaction of hydrogen has its own challenges: high energy cost and risk of explosion, requiring the extremely low temperatures. In the case of chemical storage methods by metal hydrides, the efficiency in practical use is negatively affected by hysteresis phenomena between adsorption and desorption reaction, the high heat of reaction, and low 
thermal conductivity of metal hydrides [13]. Therefore, many porous materials, including polymer-derived carbons [13,14], zeolites [15], and metal-organic frameworks, have been extensively studied as materials for hydrogen storage [16]. Among these, carbon-based porous materials, especially porous carbon fibers, has drawn the attention of scientists as the most appropriate candidates for hydrogen storage because of their high pore volume, surface area, tunable texture structure, low gas-solid interaction, and excellent chemical and thermal stability $[8,17]$. Another important reason that carbon-based porous fibers are suitable as hydrogen storage materials is that it is easy to control their pore size with sub-nanometers favoring the adsorption of large numbers of hydrogen molecules. Basically, carbon-based porous materials with sub-nanometer pores can be prepared by the successive process of carbonization and chemical activation of polymer-containing solutions. For more effective hydrogen storage, various preparation strategies, including templatebased methods, spray pyrolysis [18], and rapid thermal carbonization [19] have also been introduced as a means of controlling the pore size of carbon materials with a range of sub-hundred nanometers. Another strategy for enhancing the hydrogen storage capacity of carbon materials is the deposition of Pd nanoparticles (which have a strong affinity for hydrogen) on the surface. The improvement of the hydrogen storage capacity is closely related to the spillover effect [20] defined as the transfer of dissociative hydrogen atoms from the surface of a metal to that of the carbon substrate by a hydrogen concentration gradient induced by hydrogen affinity [21].

In this study, we developed a new strategy to achieve a high-capacity means of hydrogen storage based on carbon fibers by controlling the surface porosity (Figure 1). The core strategy is associated with forming pores both exterior and interior of the carbon fiber. First, we prepared polyvinyl alcohol/polyacrylonitrile (PVA/PAN) bi-component fibers via wet spinning, after which we removed the component (PVA) to create mainly internal pores of the fibers by immersing them in water, and by drying and calcinating them. The difference in the solubility of PVA and PAN in water is closely related to the formation of the internal pores. Subsequently, we carried out further chemical activation to create micropores and mesopores both interior and exterior of the carbon fiber. Finally, the Pd nanoparticles were electrodeposited on the surface of the carbon fiber for further improvement of the hydrogen storage capacity. Herein, we discuss the effect of the modified morphologies of the samples by successive processes-PVA removal, calcination, chemical activation and deposition of Pd nanoparticles—on their storage capacity in detail.
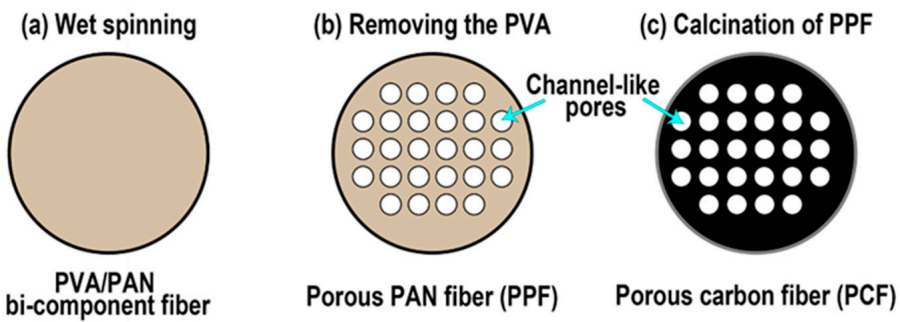

(d) Chemical activation of PCF

(e) Electrodeposition of Pd NP on APCF
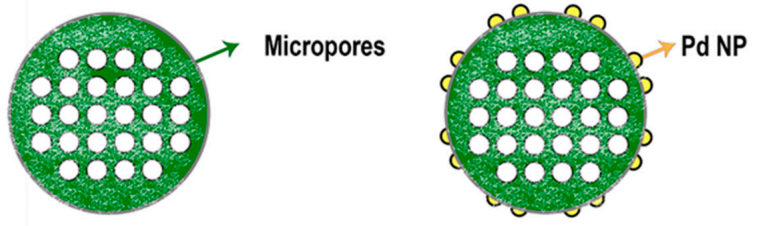

Activated PCF (APCF)

Pd deposited APCF (Pd/APCF)

Figure 1. Cross-sectional schematic illustration of (a) PVA/PAN bi-component fiber; (b) Porous PAN fiber (PPF) fabricated by removing the PVA component from the PVA/PAN bi-component fiber; (c) Porous carbon fiber (PCF) prepared by calcination of the PPF; (d) Activated PCF (APCF) prepared by chemical activation of PCF; (e) Palladium electrodeposited APCF (Pd/APCF). 


\section{Materials and Methods}

2.1. Materials

Dimethyl sulfoxide (DMSO, Duksan, Seoul, Korea, 99\%), methyl alcohol (MeOH, Duksan, Seoul, Korea, 99\%), potassium hydroxide (KOH, Duksan, Seoul, Korea, 99\%), palladium chloride ( $\mathrm{PdCl}_{2}$, Aldrich, St. Louis, MO, USA, 99\%), hydrochloric acid ( $\mathrm{HCl}$, Daejung, Siheung, Korea, $0.1 \mathrm{~N}$ ), polyacrylonitrile (PAN, Jilin Carbon Co., Ltd. Dalian, China), low-molecular-weight polyvinyl alcohol (PVA_L, Aldrich, St. Louis, MO, USA, $99 \%$, molar weight $\left(\mathrm{M}_{\mathrm{W}}\right) ; 85,000-124,000$, degree of polymerization $\left(\mathrm{D}_{\mathrm{P}}\right) ; 2000$, degree of hydrolysis $\left(\mathrm{D}_{\mathrm{H}}\right) ; 99 \%$ ) and high-molecular-weight polyvinyl alcohol (PVA_H, Aldrich, St. Louis, MO, USA, 99\%, $\mathrm{M}_{\mathrm{W}} ; 146,000-186,000, \mathrm{D}_{\mathrm{P}} ; 4000, \mathrm{D}_{\mathrm{H}} ; 99 \%$ ) were used in this study.

\subsection{Preparation of PVA/PAN Bi-Component Fiber and Porous PAN Fiber (PPF)}

The preparation of carbon fibers is summarized into four steps: (i) production of bicomponent polymeric solutions with different solubility in water; (ii) formation of PVA/PAN bi-component polymeric fibers via wet spinning (Dissol, Korea); (iii) removal of on polymeric component to create pores within the fibers; and (iv) calcination of porous polymeric fibers. Polymeric solutions of PVA_H (or PVA_L, $15 \mathrm{wt} \%$ ) and PAN (15 wt \%) were prepared by dissolving them in DMSO at $50{ }^{\circ} \mathrm{C}$. Then, dope solutions (thermodynamically stable polymer solution formed by a polymer and solvent mixture) [22] were prepared for wet spinning by mixing the PAN and PVA_H (or PVA_L) bi-component solutions at a weight ratio of 5:5, 7:3, 9:1 and 1:0 (for preparing a non-porous PAN fiber as a reference sample). The dope solutions were then extruded through a spinneret with 32 orifices (diameter; $0.1 \mathrm{~mm}$ ) and immersed in a $\mathrm{MeOH}$ coagulant at $25^{\circ} \mathrm{C}$. Subsequently, the resultants were drawn out through three continuous rollers at drawing speeds of 1,3 , and $3.4 \mathrm{~m} \mathrm{~min}^{-1}$ to form PVA/PAN bi-component fibers Figure 1a, which were then dried at $90{ }^{\circ} \mathrm{C}$ and wound onto bobbins. To fabricate the porous PAN fiber (PPF) Figure 1b, the prepared bi-component fibers were immersed in distilled water at $100{ }^{\circ} \mathrm{C}$ for $5 \mathrm{~h}$ to selectively remove PVA_H (or PVA_L) from the fibers and were finally dried in an oven at $50{ }^{\circ} \mathrm{C}$ for $24 \mathrm{~h}$.

\subsection{Preparation of Porous Carbon Fiber (PCF) and Activated Porous Carbon Fiber (APCF)}

We considered that the molecular weight of PVA and the ratio between PVA and PAN are important factors with regards to optimizing the carbon fiber porosity. With this in mind, porous carbon fibers (PCFs) were prepared by the carbonization of the asprepared PPFs in a silicon carbide tube furnace. For the carbonization of the PPFs, the temperature ramped with a constant rate of $5^{\circ} \mathrm{C} \mathrm{min}^{-1}$ from $25^{\circ} \mathrm{C}$ to $280{ }^{\circ} \mathrm{C}$ under airflow and stabilized at $280{ }^{\circ} \mathrm{C}$ for $1 \mathrm{~h}$. After that, the temperature was raised from $280{ }^{\circ} \mathrm{C}$ to $1200{ }^{\circ} \mathrm{C}$ with the temperature ramping rate of $5^{\circ} \mathrm{C} \mathrm{min}^{-1}$ under nitrogen gas and remained at the $1200{ }^{\circ} \mathrm{C}$ for $1 \mathrm{~h}$ and cooled to $25^{\circ} \mathrm{C}$. The prepared carbon fibers were denoted PCF_H 0.5, PCF_H 0.3, PCF_H 0.1 (or PCF_L 0.5, PCF_L 0.3, PCF_L 0.1), and CF depending on the concentration of PAN and PVA_H (or PVA_L) in the dope solutions, with weight ratios of 5:5, 7:3, 9:1 and 1:0 (PAN alone), respectively in Figure 1c.

For the creation of more pores, chemical activation of the PCF was carried out using a $\mathrm{KOH}$ solution. A bundle of PCFs $(0.5 \mathrm{~cm} \times 5 \mathrm{~cm}, 0.2 \mathrm{~g})$ was immersed in a $\mathrm{KOH}$ solution $(8 \mathrm{M}, 50 \mathrm{~mL})$ at $60{ }^{\circ} \mathrm{C}$ for $4 \mathrm{~h}$ and then dried at $100{ }^{\circ} \mathrm{C}$ for $24 \mathrm{~h}$. Then, the samples were calcined in a tube furnace under nitrogen flow. The temperature in the furnace was raised at a constant rate of $5^{\circ} \mathrm{C} \mathrm{min}^{-1}$ from $25^{\circ} \mathrm{C}$ to $900{ }^{\circ} \mathrm{C}$ and remained there for $1 \mathrm{~h}$. To remove any residual potassium from the activated PCFs (APCFs), the fibers were immersed in an $\mathrm{HCl}(0.1 \mathrm{~N}, 50 \mathrm{~mL})$ solution for $30 \mathrm{~min}$ and then washed repeatedly with deionized water until the $\mathrm{pH}$ of the samples became neutral. Finally, the APCFs were obtained after the drying of the samples at $100{ }^{\circ} \mathrm{C}$ for $12 \mathrm{~h}$ in an oven. The as-prepared APCFs were denoted APCF_H 0.5, APCF_H 0.3,APCF_H 0.1 (or APCF_L 0.5, APCF_L 0.3, APCF_L 0.1), ACF depending on the concentration of PAN and PVA_H (or PVA_L) in the dope solution with weight ratios of 5:5, 7:3, 9:1 and 1:0 (PAN alone), respectively (Figure 1d). 


\subsection{Electrodeposition of Pd Nanoparticles on APCF}

Among the APCFs, APCF_H 0.3 possessed the highest surface area. Therefore, Pd nanoparticles were electrodeposited on APCF_H 0.3 as reported in the literature to investigate the effect of $\mathrm{Pd}$ nanoparticles on the hydrogen storage capacity [23]. After placing a working electrode, bundles of APCF_H $0.3(0.5 \mathrm{~cm} \times 5 \mathrm{~cm}, 0.2 \mathrm{~g})$, and Pt wire counter electrode into aqueous $\mathrm{KCl}(0.1 \mathrm{mM}, 0.5 \mathrm{~mL})$ solutions containing different concentrations of $\mathrm{PdCl}_{2}(0.1,0.5$, and $1 \mathrm{mM})$, the electric field was applied at $-1.0 \mathrm{~V}$ versus the reference electrode $(\mathrm{Ag} / \mathrm{AgCl})$ for $30 \mathrm{~min}$ using a potentiostat (VSP, Bio-logic Science Instrument, France). The Pd-deposited APCF was obtained after washing with distilled water and then drying in the air (Figure 1e). Hereafter, the samples are denoted Pd 0.1/APCF_H 0.3, Pd 0.5/APCF_H 0.3 and Pd 1/APCF_H 0.3 depending on the concentration of the $\mathrm{PdCl}_{2}$ solution $(0.1,0.5,1 \mathrm{mM}$, respectively).

\subsection{Characterizations}

The surface morphology and elemental substances of the samples were analyzed by scanning electron microscopy (SU-8020, Hitachi, Tokyo, Japan) and transmission electron microscopy (HF-3300, Hitachi, Tokyo, Japan). The nitrogen adsorption-desorption isotherms at $77 \mathrm{~K}$ were used to analyze the pore size distribution, pore-volume, and specific surface area of the samples (ASAP 2020, Micromeritics, Norcross, GA, USA). The pore size distribution and micropore volume were estimated by the Horvath-Kawazoe method [24]. The hydrogen storage capacity of the samples was measured by the gravimetric method at 77 K (ISOSORP-HyGrA, Waters Corporation, Milford, MA, USA). Correlation between the hydrogen storage capacity and the specific area of the as-prepared carbon samples is calculated as the following equation:

$$
\text { Hydrogen storage capacity }(\mathrm{wt} \%)=\mathrm{K} \times \mathrm{SSA}_{\text {carbon fiber }}\left(\mathrm{m}^{2} \mathrm{~g}^{-1}\right)
$$

where $\mathrm{K}$ is a slope between hydrogen storage capacity and specific surface are of the asprepared carbon samples and SSA carbon fiber is the specific surface area of the as-prepared carbon samples.

\section{Results and Discussion}

\subsection{Surface Characterization}

For the successful fabrication of highly porous carbon fibers for hydrogen storage, the optimized PPFs should be first fabricated by selectively removing the PVA from PVA/PAN bi-component fibers. From this point of view, firstly, the effect of the molecular weight of PVA was investigated. From the cross-sectional views of the PPFs of Figure $2 a, b$, it could be seen that channel-like pores were formed on the PVA/PAN bi-component fiber via the selective removal of the PVA component. It was notable that the larger cracks were observed in PPFs prepared with a larger amount and lower molecular weight of PVA, which might be due to the aggregation of PVA. On the other hand, the morphologies of PCFs prepared by calcining these PPFs were shown in Figure 2c,d. All the PCFs exhibited channel-like macropores, showing the larger diameter in PCFs prepared with the lower molecular weight of PVA than those prepared with a higher molecular weight of PVA, similarly as shown in PPFs. It was reported that the average diameter of aggregated PVA increased as the molecular weight and viscosity decreased $[25,26]$. The surface characteristics according to the amount and molecular weight of PVA are listed in Table 1. As expected in Figure 2, it is confirmed in Table 1 that PCF_H has a larger surface area and porosity than PCF_L. In Table 1, it is also seen that PCF prepared with a PAN/PVA ratio of 7:3 and showed the best surface area and pore volume. It is natural that the surface area would become larger as PVA was the more used, since the number of pores, which resulted from the removal of PVA in PPF, might be increased. But the aggregation of PVA might also make the size of the pores larger rather than increase the number of them, leading to a decrease in surface area. As described above, the aggregation of PVA became increased in the largest amount and 
lower molecular weight of PVA. As a result, PCF_H 0.3 showed the best surface area due to such an effect and was expected to show the best hydrogen storage capacity. Actually, it was confirmed in Figure S1 that the hydrogen storage capacity was closely related to surface area and pore volume. Therefore, the effect of various treatments such as chemical activation or metal deposition will be discussed with the sample obtained by chemical activation and metal deposition treatment on PCF_H 0.3.
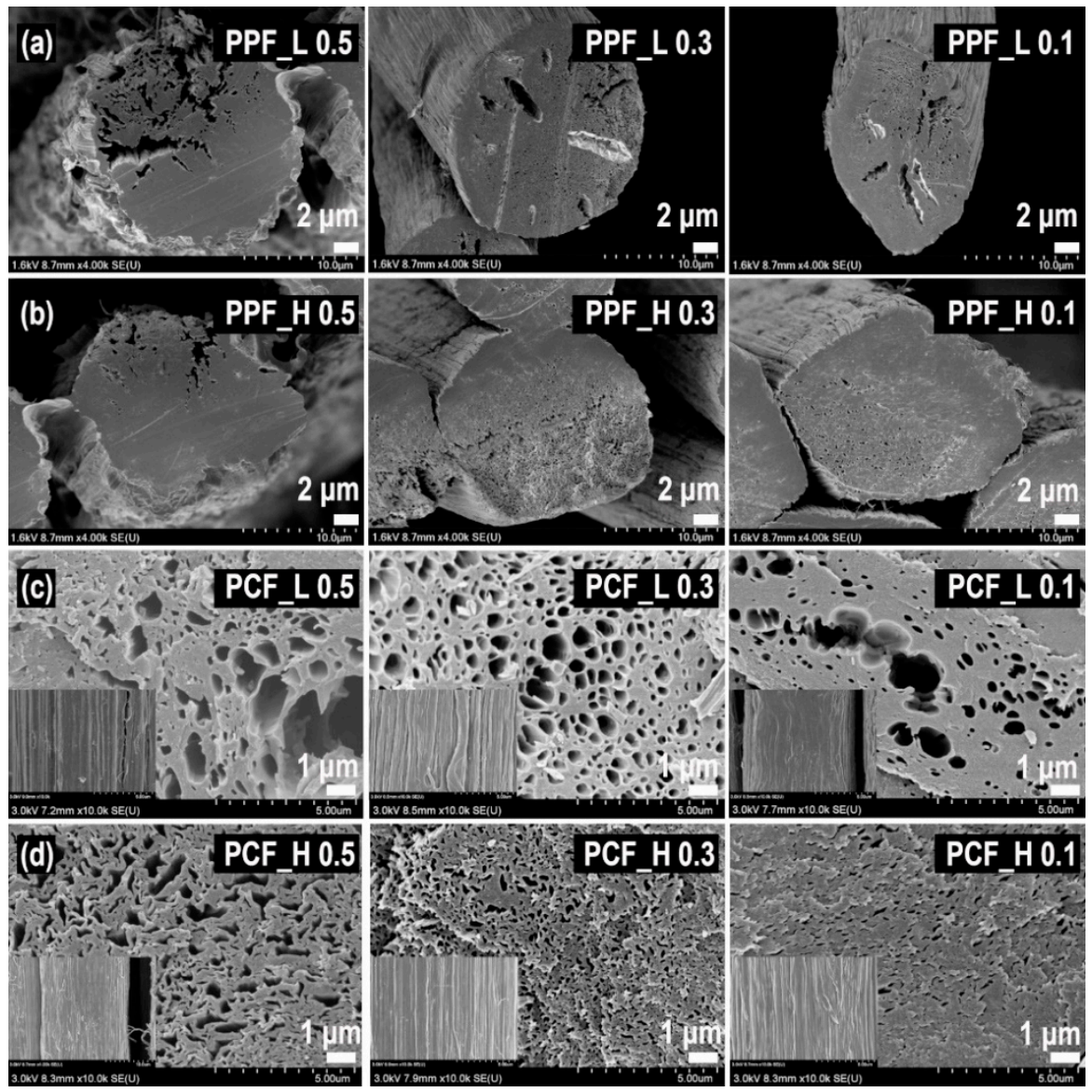

Figure 2. Cross-sectional SEM images of (a,b) PPFs (PVA-removed PAN/PVA bi-component fibers) and (c,d) porous carbon fibers (PCFs; carbonized PPFs), in which $(\mathbf{a}, \mathbf{c})$ low molecular weight PVA and $(\mathbf{b}, \mathbf{d})$ high molecular weight PVA were used when preparing the bi-component fibers. The bi-component fibers were prepared with PAN/PVA weight ratio of 5:5, 7:3, and 9:1 from left to right. The insets in (c,d) show side-view SEM images of each PCF.

Table 1. Surface area and microporosity of porous carbon fibers (PCF) prepared from dope solutions with different weight ratios of PAN and PVA.

\begin{tabular}{|c|c|c|c|c|c|}
\hline Sample & $\begin{array}{c}\text { Dope } \\
\text { Solution }\end{array}$ & Weight Ratio & $\begin{array}{c}S_{\mathrm{BET}}{ }^{1} \\
\left(\mathrm{~m}^{2} \mathrm{~g}^{-1}\right)\end{array}$ & $\begin{array}{c}V_{p}{ }^{2} \\
\left(\mathrm{~cm}^{3} g^{-1}\right)\end{array}$ & $\begin{array}{c}V_{\text {micro }}{ }^{3} \\
\left(\mathrm{~cm}^{3} \mathrm{~g}^{-1}\right)\end{array}$ \\
\hline PCF_L 0.5 & PAN/PVA_L & $5: 5$ & 201 & 0.25 & $0.12(48.0)$ \\
\hline PCF_L 0.3 & PAN/PVA_L & $7: 3$ & 424 & 0.27 & $0.16(59.2)$ \\
\hline PCF_L 0.1 & PAN/PVA_L & $9: 1$ & 110 & 0.06 & 0.02 (33.3) \\
\hline PCF_H 0.5 & PAN/PVA_H & $5: 5$ & 377 & 0.27 & 0.14 (51.9) \\
\hline PCF_H 0.3 & PAN/PVA_H & $7: 3$ & 889 & 0.47 & $0.34(72.3)$ \\
\hline PCF_H 0.1 & PAN/PVA_H & $9: 1$ & 798 & 0.46 & 0.25 (54.3) \\
\hline
\end{tabular}

${ }^{1} \mathrm{~S}_{\mathrm{BET}}$ : BET specific surface area, ${ }^{2} \mathrm{~V}_{\mathrm{P}}$ : Pore volume, estimated as $\mathrm{P} / \mathrm{P}_{0} \approx 0.99$. BET specific surface area, ${ }^{3} \mathrm{~V}_{\text {micro }}$ Micropore volume, determined by the Horvath-Kawazoe (HK) method; the percentage of the total pore volume constituted by micropores is given in parentheses. 
To improve the porosity further, PCF_H 0.3 was chemically activated with $\mathrm{KOH}$ treatment. SEM images of various carbon fibers were presented in Figure 3. The PCF shows prominently porous morphology due to the removal of PVA compared with CF (prepared by carbonization of mono-component PAN). In addition, after the treatment of chemical activation in PCF, the smooth surface in PCF was confirmed to be transformed into a highly porous surface in APCF (Figure 3f,i), which would lead to a higher surface area and porosity. The mechanism of the activation process of PCF via $\mathrm{KOH}$ is generally understood by the following three-step explanation reported in the literature elsewhere [27-29]. (i) Formation of the pore network in carbon by the etching process of a carbon framework via the redox reaction between carbon and potassium compounds; (ii) additional formation of pores by gasification of carbon promoted by the reaction between carbon and generated gases $\left(\mathrm{CO}_{2}\right.$ and $\mathrm{H}_{2} \mathrm{O}$ ); (iii) irreversible expansion of a carbon lattice by intercalation of metallic potassium into the carbon lattice. The surface area and microporosity in various types of carbon fiber, with and without chemical activation and Pd deposition, are summarized in Table 2.

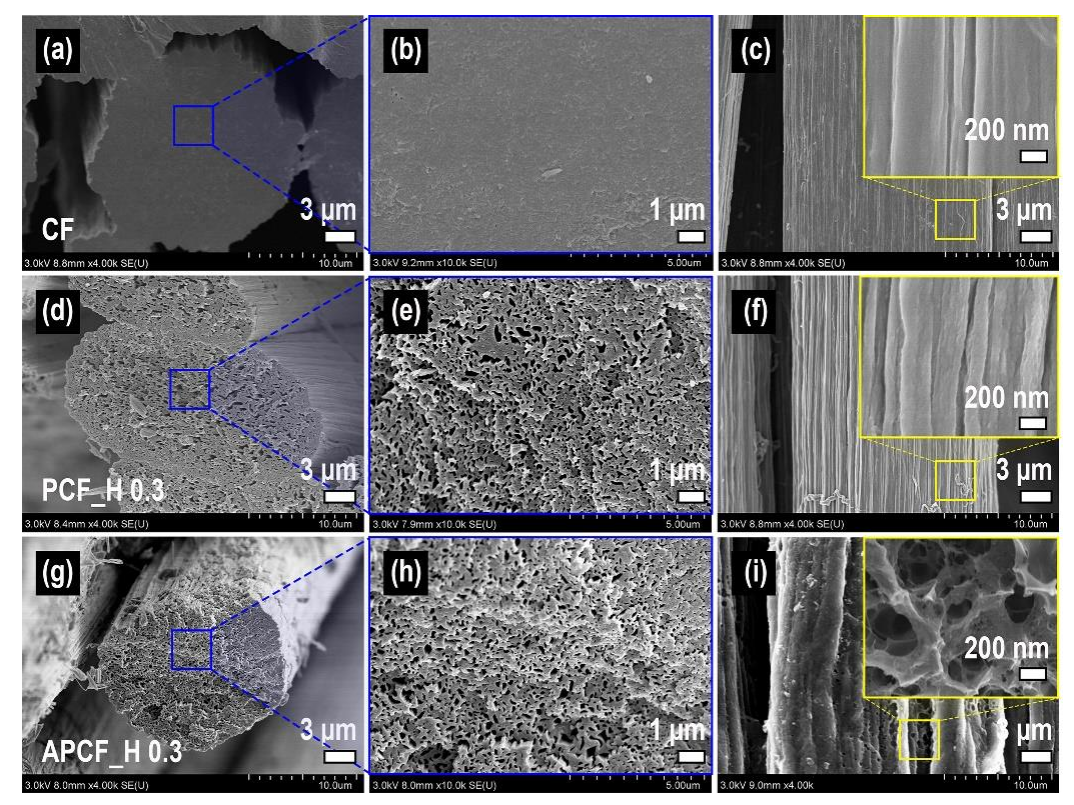

Figure 3. FE-SEM images of (a-c) carbon fiber prepared by carbonization of mono-component PAN, (d-f) PCF_H 0.3, and (g-i) APCF_H 0.3. (a,d,g) cross-section, (b,e,h) enlarged cross-section, (c,f,ii) side view (inset: enlarged side view).

Table 2. Surface area, microporosity, and hydrogen storage capacity of samples at $77 \mathrm{~K}$ and $10 \mathrm{MPa}$ in comparison with reported literature.

\begin{tabular}{|c|c|c|c|c|c|c|}
\hline Samples & $S_{B E T}{ }^{1}\left(m^{2} g^{-1}\right)$ & $V_{p}{ }^{2}\left(\mathrm{~cm}^{3} \mathrm{~g}^{-1}\right)$ & $\mathrm{V}_{\text {micro }}{ }^{3}\left(\mathrm{~cm}^{3} \mathrm{~g}^{-1}\right)$ & $W_{\text {average }}{ }^{4}(\mathrm{~nm})$ & $\mathrm{H}_{2}$ Uptake (wt\%) & Reference \\
\hline $\mathrm{CF}$ & 11 & 0.06 & $0.01(16.7)$ & 1.81 & 0.07 & This work \\
\hline $\mathrm{ACF}$ & 316 & 0.21 & $0.12(57.1)$ & 1.13 & 1.35 & This work \\
\hline PCF_H 0.3 & 889 & 0.47 & $0.34(72.3)$ & 1.12 & 2.87 & This work \\
\hline $\begin{array}{c}\text { APCF_H } \\
0.3\end{array}$ & 3058 & 1.55 & $1.18(76.1)$ & 1.05 & 5.14 & This work \\
\hline $\begin{array}{c}\text { Pd 0.5/ } \\
\text { APCF_H } 0.3\end{array}$ & 2611 & 1.43 & $1.03(72.0)$ & 1.03 & 5.45 & This work \\
\hline NF & 150 & - & - & - & 0.4 & [30] \\
\hline ANF & 265 & - & - & - & 0.6 & [30] \\
\hline ARCF1 & 1256 & - & - & - & 2.4 & [31] \\
\hline ACF A20 & 1817 & - & - & - & 3.5 & [32] \\
\hline ACF A20 & 1984 & - & - & - & 4.1 & [33] \\
\hline
\end{tabular}

${ }^{1} \mathrm{~S}_{\mathrm{BET}}$ : BET specific surface area, ${ }^{2} \mathrm{~V}_{\mathrm{P}}$ : Pore volume, estimated as $\mathrm{P} / \mathrm{P}_{0} \approx 0.99$. BET specific surface area, ${ }^{3} \mathrm{~V}_{\text {micro }}:$ Micropore volume, determined by the Horvath-Kawazoe (HK) method; the percentage of the total pore volume constituted by micropores is given in parentheses, ${ }^{4} \mathrm{~W}_{\text {average: }}$ : Average micropore width, determined using the Saito Foley method. 
PCF_H 0.3 exhibits a high BET surface area of $889 \mathrm{~m}^{2} \mathrm{~g}^{-1}$ and a pore volume of $0.47 \mathrm{~cm}^{3} \mathrm{~g}^{-1}$. The surface area is almost 80-fold that of the non-porous CF $\left(11 \mathrm{~m}^{2} \mathrm{~g}^{-1}\right)$. Importantly, the molecular weight of the PVA used in the dope solution also influences the microporosity of the sample. The fraction of micropores relative to the total pore volume increases to around $13.1 \%$ (Table 1) [34].

Alkali-mediated activation induces a significant improvement in both the BET surface area and microporosity. APCF_H 0.3 exhibits an ultra-high BET surface area of $3058 \mathrm{~m}^{2} \mathrm{~g}^{-1}$ and a pore volume of $1.55 \mathrm{~cm}^{3} \mathrm{~g}^{-1}$ (Figure 4).
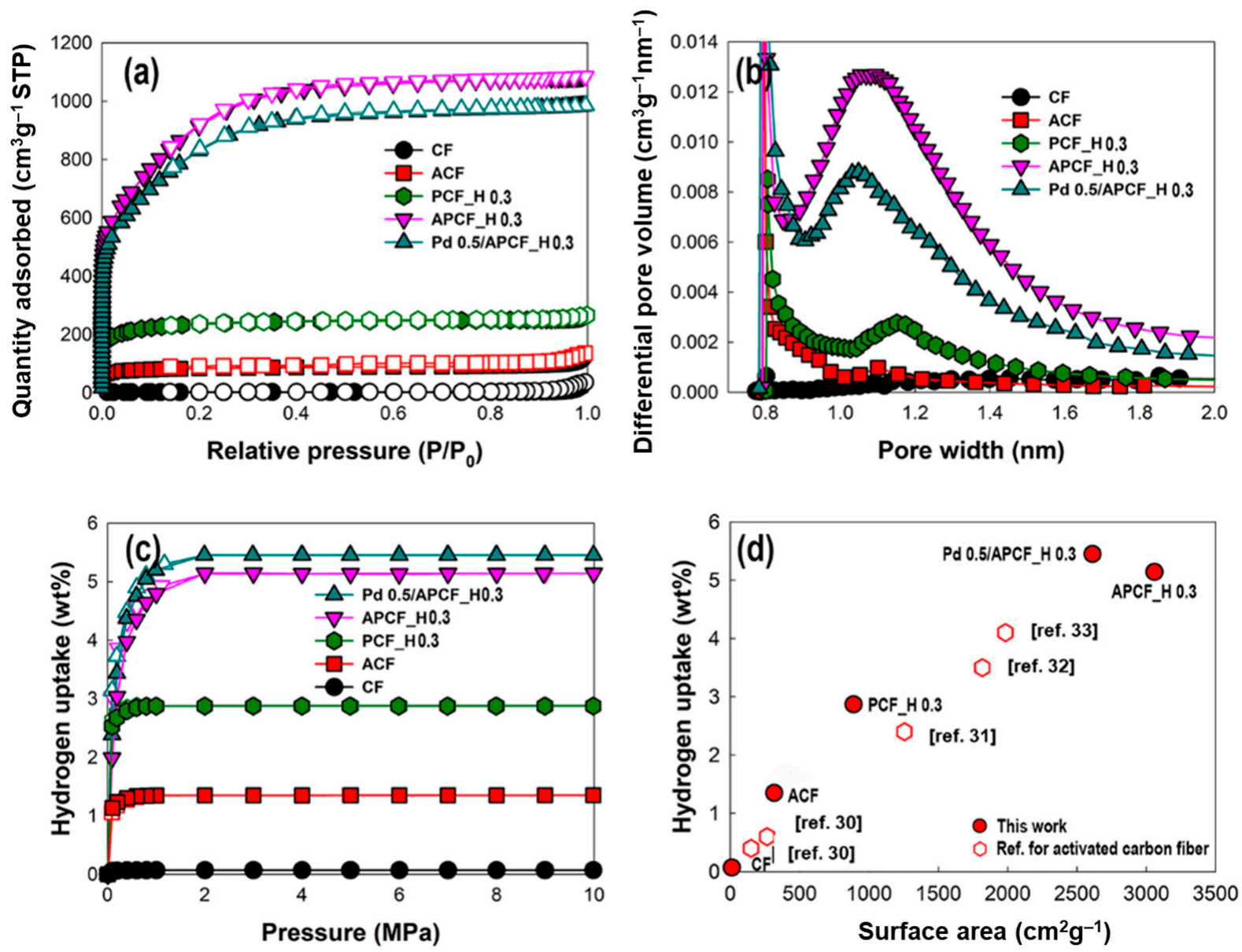

Figure 4. (a) $\mathrm{N}_{2}$ adsorption-desorption isotherm (empty-filled markers); (b) pore size distributions and (c) hydrogen uptakes of CF, ACF, PCF_H 0.3, APCF_H 0.3, and Pd 0.5/APCF_H $0.3\left(\mathrm{PdCl}_{2}\right.$ solution concentration: $\left.0.5 \mathrm{mM}\right)$; (d) Comparison of hydrogen uptake capacity (measured at $77 \mathrm{~K}$ and $10 \mathrm{MPa}$ ) vs. surface area of activated carbon fiber (empty hexagons), as reported in the literature, and as determined in the present study (filled red circles).

These values are improved over those of PCF_H 0.3 by factors 3.4 and 3.3, respectively, due to the formation of micropores and mesopores on the porous carbon fibers. Comparing APCF_H0.3 and ACF, macropore creation prior to chemical activation improves the BET surface area and pore volume by factors of 9.7 and 9.8 , respectively. The micropore size distribution of the samples is shown in Figure $4 \mathrm{~b}$. The pore sizes of PCF_H 0.3 are centered at about $1.08 \mathrm{~nm}$, making them ideal for hydrogen storage. Moreover, the number of micropores in APCF_H 0.3 with a size of $1.04 \mathrm{~nm}$ is greatly increased. This indicates that alkali-mediated activation plays a crucial role in reducing the pore size of the carbon fiber and increasing the micropore fraction. The above results show that carbon fibers with appropriate surface area and microporosity for improved hydrogen storage capacity can be successfully achieved by creating various pore sizes via (i) PVA removal from bi-component fiber and (ii) chemical activation of the porous carbon fiber. 


\subsection{The Hydrogen Storage Capacity of PCF, APCF, and Pd Deposited APCF}

In the previous section, we examined the effects of selective removal of PVA from bi-component fiber (PVA/PAN fiber), carbonization of PPFs and alkali activation of PCFs on their surface area and microporosity. Now, we discuss the relationship between these properties (surface area and microporosity) and the hydrogen storage capacity of the samples and then compare the hydrogen storage capacity of activated carbon fibers, reported elsewhere, with our results. The hydrogen storage behavior of the samples at $77 \mathrm{~K}$ and $10 \mathrm{MPa}$ is given in Table 2 and Figure 4c and Figure S2. The hydrogen storage behavior exhibits a rapid increase in the capacity below $500 \mathrm{kPa}$, but the value becomes saturated at $2 \mathrm{MPa}$. In Figure 4c, CF, ACF, PCF_H 0.3, and APCF_H 0.3, with surface areas of 11, 316, 889 , and $3058 \mathrm{~m}^{2} \mathrm{~g}^{-1}$ respectively, have hydrogen storage capacities of $0.07,1.35,2.87$, and $5.14 \mathrm{wt} \%$, respectively, at $77 \mathrm{~K}$ and $10 \mathrm{MPa}$. The results reveal that the hydrogen storage capacity is proportional to the BET surface area, which is also supported by Chahine's rule that it can adsorb $2.00 \times 10^{-3} \mathrm{wt} \%$ hydrogen gas per unit specific surface area of carbon materials $[17,35]$. The previous theoretical studies upon hydrogen storage reveal that carbon materials can adsorb hydrogen up to $2.28 \times 10^{-3} \mathrm{wt} \%$ for every unit surface area, which is the limit of the amount of hydrogen by monolayer adsorption [36]. In a similar manner as above, we can estimate the hydrogen adsorption capacity of the unit-specific surface area of carbon fibers. Equation (1) showed that as-prepared carbon fibers can adsorb the $1.41 \times 10^{-3} \mathrm{wt} \%$ hydrogen gas in every unit specific surface area at $77 \mathrm{~K}$ (Figure S1).

We especially observed that APCF_H 0.3 exhibits the best hydrogen storage capacity with the exception of Pd-deposited samples. Such a highly improved hydrogen storage capacity might originate from microporosity, which could play a crucial role in hydrogen storage. It was expected that micropores with a sufficient quantity of hydrogen storage existed in APCF_H 0.3 relative to other samples. Actually, it was observed that the chemical activation treatment of PCF_H 0.3 forms a narrower micropore with an average micropore width of $1.05 \mathrm{~nm}$ in APCF_H 0.3, which expands the micropore volume by a factor of 2.1 (Table 2). A number of micropores with a range of $0.8-1.2 \mathrm{~nm}$ in APCF_H 0.3 will be able to interact strongly with the hydrogen molecules via Van der Waals interactions, leading to an improvement in the enthalpy of adsorption $[13,37]$. It has been reported that hydrogen storage in porous carbon materials via physisorption is dominated by pores in the subnanometer range $[38,39]$. Especially, it is reported that narrow pores under $1.5 \mathrm{~nm}$ improve the hydrogen storage because the narrow pores enhance the interaction energy between hydrogen molecules and the pore walls of carbon materials [40]. However, the pore size below $0.5 \mathrm{~nm}$ is not sufficient for hydrogen storage because dynamic hydrogen molecules would not enter the inside of the pore [41]. Therefore, several groups have conducted experiments to identify the optimal pore diameter for hydrogen storage and conclude that it is $0.5-0.71 \mathrm{~nm}$ [42-45]. Moreover, theoretically, it has been estimated that the optimal pores in carbon materials for hydrogen storage should have a width of at least $0.56 \mathrm{~nm}$ at $77 \mathrm{~K}$, regardless of the pressures [46]. Several studies have also proven that the hydrogen storage capacity of carbon fibers is proportional to the micropore volume of the carbon materials [47,48]. As shown in Figure S1b, the hydrogen storage capacity of the samples shows a linear dependence on the micropore volumes of the samples. Through these observations, it was found that the largest micropore volume of APCF_H 0.3 enhances the hydrogen storage capacity (Table 2). Therefore, we can conclude that both the micropore size, especially in the case of a 1-nm pore width, as well as the micropore volume, play a crucial role in increasing the hydrogen storage capacity.

For further improvement of hydrogen capacity, Pd nanoparticles were electrodeposited onto the APCF_H 0.3. When Pd nanoparticles are deposited on APCF_H 0.3, the BET surface area falls to $2611 \mathrm{~m}^{2} \mathrm{~g}^{-1}$, the total pore volume falls to $1.42 \mathrm{~cm}^{3} \mathrm{~g}^{-1}$, and the percentage of micropore volume in total pore volume falls by $4.1 \%$. In addition, the number of pores that would constitute effective hydrogen storage $(0.8-1.2 \mathrm{~nm})$ is slightly decreased. A decreasing tendency of the surface area, pore-volume, and fraction of micropores are also observed in the Pd-deposited samples as the concentration of $\mathrm{PdCl}_{2}$ is increased. 
This indicates that the Pd nanoparticles cover the pores of APCF_H 0.3 (Table 3) [49]. As expected, the Pd nanoparticles were really found as aggregates on the APCF_H 0.3 and to partially cover most of the pores on the surface of the fibers as the concentration of the $\mathrm{PdCl}_{2}$ solution increases (Table S1 and Figure S2). The average size of Pd nanoparticles in the representative sample, Pd 0.5/APCF_H 0.3 , was $41.7 \mathrm{~nm}$. The nanoparticles were mainly composed of Pd (111) and Pd (200) planes corresponding to a lattice spacing of 0.19 and $0.22 \mathrm{~nm}$, respectively (Figure 5) [50]. The hydrogen storage capacity is increased after the electrodeposition of Pd nanoparticles on the surface of the APCF_H 0.3, at a ratio of up to $5.45 \mathrm{wt} \%$ (for a $\mathrm{PdCl}_{2}$ concentration of $0.5 \mathrm{~nm}$, Figure S3). Interestingly, when the $\mathrm{PdCl}_{2}$ concentration is increased, the hydrogen storage capacity saturates. It seemed that electro-deposited Pd nanoparticles partially blocked the micropores on the APCF_H 0.3, resulting in a decrease of the fraction of micropore volume that could be a helpful factor for hydrogen storage capacity. Simultaneously, the hydrogen storage capacity increases with the spillover effect of Pd nanoparticles that involves the following steps: (i) chemisorptive dissociation of hydrogen molecules on the Pd nanoparticles; (ii) diffusion of hydrogen atoms from Pd nanoparticles (hydrogen-rich) to the carbon substrate (hydrogen-poor); and (iii) storage of hydrogen atoms at pores of carbon substrate $[20,21,51]$. Therefore, between two conflicting effects, it is necessary to investigate which effect dominates the hydrogen storage capacity. To estimate the extent of the improvement in the hydrogen storage capacity caused by the spillover effect alone, the hydrogen storage capacity of Pd 0.5/APCF_H 0.3 via physisorption, $4.78 \mathrm{wt} \%$, was calculated by the above-mentioned empirical equation (Equation (1), Figures S1 and S3). The assumed improvement in hydrogen storage capacity resulting from the spillover effect was calculated by subtracting the calculated hydrogen storage capacity from the experimental result. Hence, the improvement caused by the spillover effect was determined to be around $0.67 \mathrm{wt} \%$. These results indicate that there is a competitive relationship between the physisorption by alkali activation and chemisorption by the spillover effect [52-54]. Therefore, for the application of metal-deposited carbon fiber in hydrogen storage, the effect of metal nanoparticles on micropore volume and pore size of the metal deposited-carbon fiber would have to be considered together with a spillover effect $[55,56]$.

Table 3. Surface area, microporosity, and hydrogen storage capacity at $77 \mathrm{~K}$ and $10 \mathrm{MPa}$ of Pd-deposited APCF_H 0.3.

\begin{tabular}{|c|c|c|c|c|c|}
\hline Sample & $\begin{array}{c}{\left[\mathrm{PdCl}_{2}\right]} \\
(\mathrm{mM})\end{array}$ & $\begin{array}{c}\mathrm{S}_{\mathrm{BET}}{ }^{1} \\
\left(\mathrm{~m}^{2} \mathrm{~g}^{-1}\right)\end{array}$ & $\begin{array}{c}V_{p^{2}} \\
\left(\mathrm{~cm}^{3} g^{-1}\right)\end{array}$ & $\begin{array}{c}V_{\text {micro }}{ }^{3} \\
\left(\mathrm{~cm}^{3} \mathrm{~g}^{-1}\right)\end{array}$ & $\mathrm{H}_{2}$ Storage (wt $\left.\%\right)$ \\
\hline APCF_H 0.3 & 0 & 3058 & 1.55 & $1.18(76.1)$ & 5.14 \\
\hline Pd 0.1/APCF_H 0.3 & 0.1 & 2760 & 1.44 & $1.05(72.9)$ & 5.30 \\
\hline Pd 0.5/APCF_H 0.3 & 0.5 & 2611 & 1.43 & $1.03(72.0)$ & 5.45 \\
\hline Pd 1/APCF_H 0.3 & 1 & 2503 & 1.40 & $1.00(71.4)$ & 5.17 \\
\hline
\end{tabular}

${ }^{1} \mathrm{~S}_{\mathrm{BET}}$ : BET specific surface area, ${ }^{2} \mathrm{~V}_{\mathrm{P}}$ : Pore volume, estimated as $\mathrm{P} / \mathrm{P}_{0} \approx 0.99$. BET specific surface area, ${ }^{3} \mathrm{~V}_{\text {micro }}$ : Micropore volume, determined by the Horvath-Kawazoe (HK) method; the percentage of the total pore volume constituted by micropores is given in parentheses.

\subsection{APCF with an Excellent Hydrogen Storage Capacity}

As shown in Figure 4d, the hydrogen storage capacity and surface area of carbon fibers reported elsewhere were compared with those of our samples [30-33]. The literature states that both carbon fibers and activated carbon fibers have small surface areas (150 and $265 \mathrm{~m}^{2} \mathrm{~g}^{-1}$, respectively) and hydrogen storage capacity (0.4 and $0.6 \mathrm{wt} \%$, respectively) due to their intrinsic morphologies. However, here, the optimal porous carbon fiber (PCF_H 0.3) and activated porous carbon fiber (APCF_H 0.3) have an extremely larger surface area and higher hydrogen storage capacity than carbon fibers and activated carbon fibers (Table 2). Interestingly, the hydrogen storage capacity of APCF_H 0.3 is similar to that of an activated carbon aerogel produced using $\mathrm{CO}_{2}, 5.3 \mathrm{wt} \%$ [17]. Furthermore, the hydrogen storage capacity of APCF_H 0.3, $5.14 \mathrm{wt} \%$, is higher than that of carbon fibers reported elsewhere [30-33]. This comparison indicates that our strategy for controlling the porosity of carbon fibers is extremely promising for advancing hydrogen storage. 

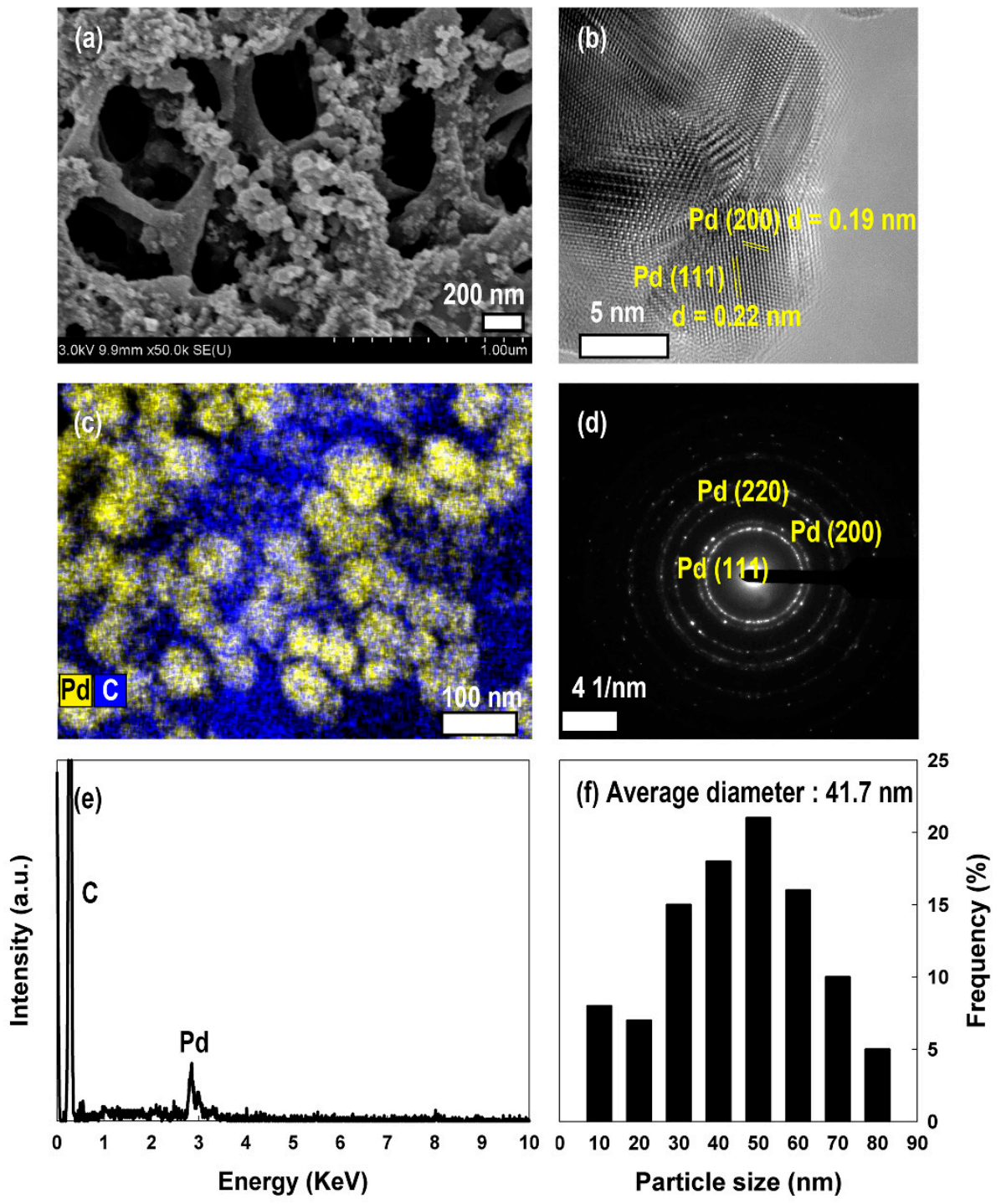

Figure 5. (a) SEM image, (b) TEM image, (c) EDS elemental mapping image, (d) SAED pattern, and (e) EDS spectrum of Pd 0.5/APCF_H 0.3. (f) Diameter distribution of Pd nanoparticles in the sample, Pd0.5/APCF_H 0.3.

\section{Conclusions}

In the present study, porous carbon fiber and activated porous carbon fiber were prepared via the carbonization and alkali activation of PVA/PAN bi-component fibers from which the PVA had been selectively removed. We found that the pore size of the carbon fiber decreased as the molar weight of the PVA increased. The surface activation of porous carbon fiber leads to a tremendous increase in the surface area $\left(3058 \mathrm{~m}^{2} \mathrm{~g}^{-1}\right)$ and micropore volume $\left(1.18 \mathrm{~cm}^{3} \mathrm{~g}^{-1}\right)$ of the fiber. The improved surface area and microporosity of the carbon fiber enhanced the hydrogen storage capacity via physisorption to $5.14 \mathrm{wt} \%$. To the best of our knowledge, this value is higher than those of previously reported carbon fibers. For further improvement of hydrogen storage capacity, Pd nanoparticles were electrodeposited on the chemically activated porous carbon fiber. It was revealed that the hydrogen storage capacity of Pd-deposited activated porous carbon fiber is $5.45 \mathrm{wt} \%$ at $77 \mathrm{~K}$ and $10 \mathrm{MPa}$. In summary, we developed a new strategy to achieve a high-capacity means of hydrogen storage on the basis of carbon fibers by controlling the surface porosity. The core strategy is associated with forming pores both exterior and interior of the carbon fiber using the polyvinyl alcohol/polyacrylonitrile (PVA/PAN) bi-component fibers. The difference in the solubility of PVA and PAN in water is closely related to the formation of the internal pores. This 
method is found to be very effective to improve the pore characteristics of carbon fibers by way of successive chemical activation. Finally, the Pd nanoparticles were electrodeposited on the surface of the carbon fiber for further improvement of the hydrogen storage capacity; however, it was also found that the enhancement in hydrogen storage capacity via a spillover effect due to deposition of Pd nanoparticles is relatively low ( $\sim 0.3 \mathrm{wt} \%)$ due to deposition of $\mathrm{Pd}$ nanoparticles, since the micropores of the activated porous area were partially covered by the deposition of $\mathrm{Pd}$ nanoparticles. For the application of metaldeposited carbon fiber in hydrogen storage, the effect of metal nanoparticles on pore characteristics in metal deposited-carbon fiber would have to be considered together with spillover effect. We believe that the proposed method which involves the control of the surface morphology of the carbon fibers and Pd deposition on their surfaces could provide high hydrogen storage capacity.

Supplementary Materials: The following are available online at https:/ / www.mdpi.com/article/10 .3390 / nano11071830/s1, Table S1. The atomic percentage of Pd-deposited APCF_H 0.3. Figure S1. Correlation plot of (a) BET surface area and hydrogen uptake of the samples (b) micropore volume and hydrogen uptake of the samples: CF (empty circle), ACF (empty rectangle), PCF (filled circles), APCF (filled rectangles), Pd-deposited APCF (filled triangles). The samples prepared from dope solutions with different weight ratios of PAN and low-molecular-weight PVA are indicated in red. The samples prepared from dope solutions with different weight ratios of PAN and high-molecularweight PVA are indicated in blue. Figure S2. FE-SEM image of the (a-d) Pd-deposited APCF_H 0.3 with different concentrations of $\mathrm{PdCl}_{2}$ solution: (a) $0 \mathrm{mM}$, (b) $0.1 \mathrm{mM}$, (c) $0.5 \mathrm{mM}$, and (d) $1 \mathrm{mM}$. Figure S3. $\mathrm{N}_{2}$ adsorption (empty) and desorption (filled) isotherms of (a) Pd-deposited APCF_H 0.3. (b) Hydrogen up-takes of Pd-deposited APCF_H with different concentrations of $\mathrm{PdCl}_{2}$ solutions (0 mM (black circles), $0.1 \mathrm{mM}$ (red rectangles), $0.5 \mathrm{mM}$ (blue rhomboids), and $1 \mathrm{mM}$ (green hexagons). Inset figure: enlarged graphs of hydrogen uptake behavior of samples.

Author Contributions: Conceptualization, S.-H.H. and S.K.L.; data curation, Y.K.K., H.-J.S. and S.M.J.; formal analysis, Y.K.K.; methodology, Y.K.K. and H.-J.S.; project administration, S.K.L.; supervision, S.K.L.; writing-original draft, S.-H.H. and Y.K.K.; writing—review and editing, S.-H.H., J.K. and S.K.L. All authors have read and agreed to the published version of the manuscript.

Funding: This research was funded by DGIST R \& D Program of Ministry of Science and ICT of the Republic of Korea, grant number 21-ET-08.

Data Availability Statement: Not applicable.

Conflicts of Interest: The authors declare no conflict of interest.

\section{References}

1. Park, J.H.; Ramasamy, P.; Kim, S.; Kim, Y.K.; Ahilan, V.; Shanmugam, S.; Lee, J.S. Hybrid metal—Cu2S nanostructures as efficient co-catalysts for photocatalytic hydrogen generation. Chem. Commun. 2017, 53, 3277-3280. [CrossRef] [PubMed]

2. Moliner, R.; Lázaro, M.J.; Suelves, I. Analysis of the strategies for bridging the gap towards the hydrogen economy. Int. J. Hydrogen Energy 2016, 41, 19500-19508. [CrossRef]

3. Preuster, P.; Papp, C.; Wasserscheid, P. Liquid organic hydrogen carriers (LOHCs): Toward a hydrogen-free hydrogen economy. Acc. Chem. Res. 2017, 50, 74-85. [CrossRef] [PubMed]

4. Choi, S.K.; Piao, G.; Choi, W.; Park, H. Highly efficient hydrogen production using p-Si wire arrays and NiMoZn heterojunction photocathodes. Appl. Catal. B Environ. 2017, 217, 615-621. [CrossRef]

5. Kim, Y.K.; Park, H. How and to what extent do carbon materials catalyze solar hydrogen production from water? Appl. Catal. $B$ Environ. 2012, 125, 530-537. [CrossRef]

6. Kim, Y.K.; Park, H. Light-harvesting multi-walled carbon nanotubes and CdS hybrids: Application to photocatalytic hydrogen production from water. Energy Environ. Sci. 2011, 4, 685-694. [CrossRef]

7. Kim, Y.K.; Lim, S.K.; Park, H.; Hoffmann, M.R.; Kim, S. Trilayer CdS/carbon nanofiber (CNF) mat/Pt-TiO 2 composite structures for solar hydrogen production: Effects of CNF mat thickness. Appl. Catal. B Environ. 2016, 196, 216-222. [CrossRef]

8. Hwang, S.-H.; Choi, W.M.; Lim, S.K. Hydrogen storage characteristics of carbon fibers derived from rice straw and paper mulberry. Mater. Lett. 2016, 167, 18-21. [CrossRef]

9. Liu, C.; Chen, Y.; Wu, C.-Z.; Xu, S.-T.; Cheng, H.-M. Hydrogen storage in carbon nanotubes revisited. Carbon 2010, 48, 452-455. [CrossRef] 
10. Isidro-Ortega, F.J.; Pacheco-Sánchez, J.H.; Desales-Guzmán, L.A. Hydrogen storage on lithium decorated zeolite templated carbon, DFT study. Int. J. Hydrog. Energy 2017, 42, 30704-30717. [CrossRef]

11. Wang, Q. Transportation of hydrogen molecules using carbon nanotubes in torsion. Carbon 2009, 47, 1870-1873. [CrossRef]

12. Zhang, F.; Zhao, P.; Niu, M.; Maddy, J. The survey of key technologies in hydrogen energy storage. Int. J. Hydrog. Energy 2016, 41, 14535-14552. [CrossRef]

13. Xia, Y.; Yang, Z.; Zhu, Y. Porous carbon-based materials for hydrogen storage: Advancement and challenges. J. Mater. Chem. A 2013, 1, 9365-9381. [CrossRef]

14. Rochat, S.; Polak-Krasna, K.; Tian, M.; Holyfield, L.T.; Mays, T.J.; Bowen, C.R.; Burrows, A.D. Hydrogen storage in polymer-based processable microporous composites. J. Mater. Chem. A 2017, 5, 18752-18761. [CrossRef]

15. Dong, J.; Wang, X.; Xu, H.; Zhao, Q.; Li, J. Hydrogen storage in several microporous zeolites. Int. J. Hydrog. Energy 2007, 32, 4998-5004. [CrossRef]

16. Gygi, D.; Bloch, E.D.; Mason, J.A.; Hudson, M.R.; Gonzalez, M.I.; Siegelman, R.L.; Darwish, T.A.; Queen, W.L.; Brown, C.M.; Long, J.R. Hydrogen storage in the expanded pore metal-organic frameworks M2(dobpdc) (M = Mg, Mn, Fe, Co, Ni, Zn). Chem. Mater. 2016, 28, 1128-1138. [CrossRef]

17. Kabbour, H.; Baumann, T.F.; Satcher, J.H.; Saulnier, A.; Ahn, C.C. Toward new candidates for hydrogen storage: High-surface-area carbon aerogels. Chem. Mater. 2006, 18, 6085-6087. [CrossRef]

18. Zhang, L.; Liu, X.; Dou, Y.; Zhang, B.; Yang, H.; Dou, S.; Liu, H.; Huang, Y.; Hu, X. Mass production and pore size control of holey carbon microcages. Angew. Chem. Int. Ed. 2017, 56, 13790-13794. [CrossRef]

19. Fang, D.Z.; Striemer, C.C.; Gaborski, T.R.; McGrath, J.L.; Fauchet, P.M. Pore size control of ultrathin silicon membranes by rapid thermal carbonization. Nano Lett. 2010, 10, 3904-3908. [CrossRef]

20. Konda, S.K.; Chen, A. Palladium based nanomaterials for enhanced hydrogen spillover and storage. Mater. Today 2016, 19, 100-108. [CrossRef]

21. Boudart, M.; Vannice, M.A.; Benson, J.E. Adlineation, portholes and spillover. Z. Für Phys. Chem. 1969, 64, 171-177. [CrossRef]

22. Mohamed, K. Dope solution. In Encyclopedia of Membranes; Drioli, E., Giorno, L., Eds.; Springer: Berlin/Heidelberg, Germany, 2015; pp. 1-3. [CrossRef]

23. Horváth, G.; Kawazoe, K. Method for the calculation of effective pore size distribution in molecular sieve carbon. J. Chem. Eng. Jpn. 1983, 16, 470-475. [CrossRef]

24. Kim, Y.K.; Seo, H.-J.; Kim, S.; Hwang, S.-H.; Park, H.; Lim, S.K. Effect of ZnO electrodeposited on carbon film and decorated with metal nanoparticles for solar hydrogen production. J. Mater. Sci. Technol. 2016, 32, 1059-1065. [CrossRef]

25. Yue, Z.; Economy, J.; Mangun, C.L. Preparation of fibrous porous materials by chemical activation 2. H3PO4 activation of polymer coated fibers. Carbon 2003, 41, 1809-1817. [CrossRef]

26. Lee, J.S.; Choi, K.H.; Ghim, H.D.; Kim, S.S.; Chun, D.H.; Kim, H.Y.; Lyoo, W.S. Role of molecular weight of atactic poly(vinyl alcohol) (PVA) in the structure and properties of PVA nanofabric prepared by electrospinning. J. Appl. Polym. Sci. 2004, 93, 1638-1646. [CrossRef]

27. Wang, J.; Kaskel, S. KOH activation of carbon-based materials for energy storage. J. Mater. Chem. 2012, 22, 23710-23725. [CrossRef]

28. Diez, N.; Alvarez, P.; Granda, M.; Blanco, C.; Santamaria, R.; Menendez, R. A novel approach for the production of chemically activated carbon fibers. Chem. Eng. J. 2015, 260, 463-468. [CrossRef]

29. Lillo-Ródenas, M.A.; Cazorla-Amorós, D.; Linares-Solano, A. Understanding chemical reactions between carbons and NaOH and $\mathrm{KOH}$ : An insight into the chemical activation mechanism. Carbon 2003, 41, 267-275. [CrossRef]

30. Jordá-Beneyto, M.; Suárez-García, F.; Lozano-Castelló, D.; Cazorla-Amorós, D.; Linares-Solano, A. Hydrogen storage on chemically activated carbons and carbon nanomaterials at high pressures. Carbon 2007, 45, 293-303. [CrossRef]

31. Xu, W.C.; Takahashi, K.; Matsuo, Y.; Hattori, Y.; Kumagai, M.; Ishiyama, S.; Kaneko, K.; Iijima, S. Investigation of hydrogen storage capacity of various carbon materials. Int. J. Hydrog. Energy 2007, 32, 2504-2512. [CrossRef]

32. Purewal, J.J.; Kabbour, H.; Vajo, J.J.; Ahn, C.C.; Fultz, B. Pore size distribution and supercritical hydrogen adsorption in activated carbon fibers. Nanotechnology 2009, 20, 204012. [CrossRef] [PubMed]

33. Gao, F.; Zhao, D.-L.; Li, Y.; Li, X.-G. Preparation and hydrogen storage of activated rayon-based carbon fibers with high specific surface area. J. Phys. Chem. Solids 2010, 71, 444-447. [CrossRef]

34. Sevilla, M.; Sangchoom, W.; Balahmar, N.; Fuertes, A.B.; Mokaya, R. Highly porous renewable carbons for enhanced storage of energy-related gases $\left(\mathrm{H}_{2}\right.$ and $\left.\mathrm{CO}_{2}\right)$ at high pressures. ACS Sustain. Chem. Eng. 2016, 4, 4710-4716. [CrossRef]

35. Goldsmith, J.; Wong-Foy, A.G.; Cafarella, M.J.; Siegel, D.J. Theoretical limits of hydrogen storage in metal-organic frameworks: Opportunities and trade-offs. Chem. Mater. 2013, 25, 3373-3382. [CrossRef]

36. Züttel, A.; Sudan, P.; Mauron, P.; Wenger, P. Model for the hydrogen adsorption on carbon nanostructures. Appl. Phys. A 2004, 78, 941-946. [CrossRef]

37. Wang, Q.; Johnson, J.K. Molecular simulation of hydrogen adsorption in single-walled carbon nanotubes and idealized carbon slit pores. J. Chem. Phys. 1999, 110, 577-586. [CrossRef]

38. Kadono, K.; Kajiura, H.; Shiraishi, M. Dense hydrogen adsorption on carbon subnanopores at 77 K. Appl. Phys. Lett. 2003, 83, 3392-3394. [CrossRef]

39. Felderhoff, M.; Weidenthaler, C.; von Helmolt, R.; Eberle, U. Hydrogen storage: The remaining scientific and technological challenges. Phys. Chem. Chem. Phsy. 2007, 9, 2643-2653. [CrossRef] 
40. Czakkel, O.; Nagy, B.; Dobos, G.; Fouquet, P.; Bahn, E.; László, K. Static and dynamic studies of hydrogen adsorption on nanoporous carbon gels. Int. J. Hydrog. Energy 2019, 44, 18169-18178. [CrossRef]

41. Im, J.S.; Park, S.-J.; Kim, T.J.; Kim, Y.H.; Lee, Y.-S. The study of controlling pore size on electrospun carbon nanofibers for hydrogen adsorption. J. Colloid Interface Sci. 2008, 318, 42-49. [CrossRef] [PubMed]

42. Patchkovskii, S.; Tse, J.S.; Yurchenko, S.N.; Zhechkov, L.; Heine, T.; Seifert, G. Graphene nanostructures as tunable storage media for molecular hydrogen. Proc. Natl. Acad. Sci. USA 2005, 102, 10439-10444. [CrossRef] [PubMed]

43. Gogotsi, Y.; Portet, C.; Osswald, S.; Simmons, J.M.; Yildirim, T.; Laudisio, G.; Fischer, J.E. Importance of pore size in high-pressure hydrogen storage by porous carbons. Int. J. Hydrog. Energy 2009, 34, 6314-6319. [CrossRef]

44. Rzepka, M.; Lamp, P.; de la Casa-Lillo, M.A. Physisorption of hydrogen on microporous carbon and carbon nanotubes. J. Phys. Chem. B 1998, 102, 10894-10898. [CrossRef]

45. Georgiev, P.A.; Ross, D.K.; Albers, P.; Ramirez-Cuesta, A.J. The rotational and translational dynamics of molecular hydrogen physisorbed in activated carbon: A direct probe of microporosity and hydrogen storage performance. Carbon 2006, 44, $2724-2738$. [CrossRef]

46. Cabria, I.; López, M.J.; Alonso, J.A. Simulation of the hydrogen storage in nanoporous carbons with different pore shapes. Int. J. Hydrog. Energy 2011, 36, 10748-10759. [CrossRef]

47. Sevilla, M.; Alam, N.; Mokaya, R. Enhancement of hydrogen storage capacity of zeolite-templated carbons by chemical activation. J. Phys. Chem. C 2010, 114, 11314-11319. [CrossRef]

48. de la Casa-Lillo, M.A.; Lamari-Darkrim, F.; Cazorla-Amorós, D.; Linares-Solano, A. Hydrogen storage in activated carbons and activated carbon fibers. J. Phys. Chem. B 2002, 106, 10930-10934. [CrossRef]

49. Wenelska, K.; Michalkiewicz, B.; Chen, X.; Mijowska, E. Pd nanoparticles with tunable diameter deposited on carbon nanotubes with enhanced hydrogen storage capacity. Energy 2014, 75, 549-554. [CrossRef]

50. Zhang, T.; Nakagawa, Y.; Wakasugi, T.; Isobe, S.; Wang, Y.; Hashimoto, N.; Ohnuki, S. Hydrogen absorption of palladium thin films observed by in situ transmission electron microscopy with an environmental cell. ACS Appl. Mater. Interfaces 2016, 8, 14548-14551. [CrossRef]

51. Lachawiec, A.J.; Qi, G.; Yang, R.T. Hydrogen storage in nanostructured carbons by spillover: Bridge-building enhancement. Langmuir 2005, 21, 11418-11424. [CrossRef]

52. Chen, Z.; Li, P.; Anderson, R.; Wang, X.; Zhang, X.; Robison, L.; Redfern, L.R.; Moribe, S.; Islamoglu, T.; Gómez-Gualdrón, D.A.; et al. Balancing volumetric and gravimetric uptake in highly porous materials for clean energy. Science 2020, 368, 297-303. [CrossRef] [PubMed]

53. Blankenship, L.S.; Mokaya, R. Cigarette butt-derived carbons have ultra-high surface area and unprecedented hydrogen storage capacity. Energy Environ. Sci. 2017, 10, 2552-2562. [CrossRef]

54. Gadipelli, S.; Guo, Z.X. Graphene-based materials: Synthesis and gas sorption, storage and separation. Prog. Mater. Sci. 2015, 69, 1-60. [CrossRef]

55. Chen, T.; Zhou, Y.; Luo, L.; Wu, X.; Li, Z.; Fan, M.; Zhao, W. Preparation and characterization of heteroatom self-doped activated biocarbons as hydrogen storage and supercapacitor electrode materials. Electrochim. Acta 2019, 325, 134941. [CrossRef]

56. Gadipelli, S.; Howard, C.A.; Guo, J.; Skipper, N.T.; Zhang, H.; Shearing, P.R.; Brett, D.J.L. Superior Multifunctional Activity of Nanoporous Carbons with Widely Tunable Porosity: Enhanced Storage Capacities for Carbon-Dioxide, Hydrogen, Water, and Electric Charge. Adv. Energy Mater. 2020, 10, 1903649. [CrossRef] 